\title{
Perancangan Sistem Keamanan Brangkas Menggunakan Pengenalan Wajah Berbasis Android
}

\author{
Gilang Aditya Rama*, Fauziah, Nurhayati \\ Fakultas Teknologi Komunikasi dan Informatika, Universitas Nasional, Jakarta, Indonesia \\ Email: 1,*gilangadityarama9@ gmail.com, ${ }^{2}$ fauziah@civitas.unas.ac.id, ${ }^{3}$ nurh4y@gmail.com \\ Email Penulis Korespondensi: gilangadityarama9@gmail.com
}

\begin{abstract}
Abstrak-Tingkat keamanan pada hal akses menjadi salah satu prioritas utama setiap orang untuk meningkatkan sistem keamanan yang dirasa perlu adanya peningkatan mengikuti perkembangan teknologi modern. Penelitian ini membahas tentang sebuah sistem keamanan brangkas menggunakan face recognition yang berbasisAndroid. Penelitian bertujuan agar sistem keamanan brangkas memiliki tingkat keamanan yang lebih baik dari sistem sebelumnya. Tahap awal untuk membangun sistem ini, penulis melakukan tahap pengumpulan data secara literatur sebagai dasar teori dan metode pengembangan sistem yang digunakan oleh perancang perangkat lunak sebelumnya ialah metode waterfall, secara umum metode ini terbagi menjadi beberapa tahapan, diantaranya: Analisis, Desain, Kode Program dan Pengujian Unit. Untuk metode yang digunakan pada penelitian sistem ini adalah metode algoritma eigenfaces untuk tahap pendeteksian objek wajah pada proses awal training image. Serta metode algoritma Local Binary Patterns dan Histrogram Equalization pada tahap membaca gambar pengenalan wajah si pengguna secara akurat yang memiliki tingkat keakuratan membaca wajah hingga 95.56\%. Hasil data wajah user akan diproses di Wemos D1 dan data akan dikirim dan disimpan dalam database. Hasil data dari data face recognition akan digunakan lagi sebagai data user untuk membuka brangkas. Kesimpulan yang didapat, sistem dapat membaca wajah user secara real time dan dapat bekerja secara baik untuk sistem keamanan brangkas.
\end{abstract}

Kata Kunci: Android, Kamera, Pengenalan Wajah, Waterfall dan Wemos D1.

Abstract-The level of security in terms of access is one of the main priorities of everyone to improve the security system that feels the need for improvement following the development of modern technology. This study discusses a security system using Android-based face recognition. The aim of this research is that the safe safety system has a better level of security than the previous system. The initial stage to build this system, the authors do the literature data collection stage as a basis for the theory and system development methods used by software designers before is the waterfall method, in general this method is divided into several stages, including: Analysis, Design, Program Code and Unit Testing. For the method used in the research of this system is the eigenfaces algorithm method for the detection of facial objects in the initial process of image training. As well as the Local Binary Patterns algorithm method and Histrogram Equalization at the stage of reading the user's face recognition image accurately which has an accuracy of face reading up to $95.56 \%$. The results of the user's face data will be processed in Wemos D1 and the data will be sent and stored in a database. The results of data from face recognition data will be used again as user data to open the safe. The conclusion, the system can read the user's face in real time and can work well for safe security systems.

Keywords: Android, Camera, Face Recognition, Waterfall and Wemos D1.

\section{PENDAHULUAN}

Sesuai dengan perkembangan ilmu dan teknologi yang ada pada masa kini, yang menjadi sorotan untuk pengembangan sistem yaitu sistem identifikasi yang sekarang ini sedang banyak digunakan di era modern ialah proses mengidentifkasi menggunakan informasi biologis seperti wajah, retina, dan bagian anggota tubuh lainnya. Salah satu identifikasi yang memiliki tingkat keakuratan tinggi yaitu wajah. Wajah setiap orang memiliki keunikan yang berbeda-beda untuk di identifikasi. Identifikasi tersebut dapat digunakan untuk membuka sebuah kunci brangkas yang ber isi barang-barang [1]. Wajah merupakan salah satu bagian dari manusia yang memiliki ciri berbeda dari yang lain-nya. Wajah dapat digunakan untuk mengenali seseorang, seperti kebutuhan absensi, pendataan penduduk, dan sistem keamanan, dengan menggunakan sistem pengenalan wajah [2]. Karena memiliki ciri yang berbeda wajah menjadi salah satu sistem keamanan yang sulit ditembus, seperti dari pencahayaan, warna kulit, potongan rambut, kacamata serta posisi wajah yang bebeda yang dalam keadaan menunduk, menoleh atau mengadah [3].

Pada penelitian sebelumnya sudah ada sistem pengenalan wajah menggunakan metode Hidden Markov Models (HMM) yang mencapai tingkat akurasi sebesar 84,28\%, dengan database 70 gambar yang terdiri dari 10 individu dengan masing-masing memiliki perbedaan. Dan penelitian ini pun sudah menggunakan eigenfaces juga untuk mendukung posisi dari tampak wajah mulai dari tampak depan, atas, bawah, kanan, kiri, ukuran kecahayan dan latar belakang [4]. Dalam penelitian yang akan dibahas pada penulisan ini yang berjudul "Perancangan Sistem Keamanan Brangkas Menggunakan Pengenalan Wajah Berbasis Android". Dalam tahap peracnangan sistem yang akan dibangun ini penulis menggunakan metode LBPH yang memiliki tingkat akurasi paling besar saat ini yaitu 95,56\%. Dengan menggunakan eigenfaces untuk mendukung tampak citra yang lebih luas sehingga pengguna tak perlu harus selalu tegak lurus menghadap kamera [5][6]. Eigenfaces menggunakan analisa komponen utama dari wajah atau foto wajah. Analisa ini dilakukan hanya menggunakan fitur yang sangat penting untuk pengenalan wajah. Eigenfaces adalah satu set vector eigen yang digunakan untuk membaca wajah manusia. Metode ini Dikembangkan oleh (Sirivich dan Kriby. 1987) dan digunakan oleh Matthew Turk dan Alex Pentland dalam klasifikasi wajah [7][8]. 
Tujuan dilakukannya penelitian ini, yaitu agar sistem dapat melakukan buka brangkas secara otomatisdan sistem dapat melakukan pendeteksian dan pengenalan wajah secara akurat.

\section{METODOLOGI PENELITIAN}

Penelitian "Perancangan Sistem Keamanan Brangkas Menggunakan Pengenalan Wajah Berbasis Android" ini dilakukan dengan beberapa tahap-tahap penelitian yang menjadi dasar pembentukan dan perancangan sistem [5].

\subsection{Tahap Pengumpulan Data}

Untuk tahap pengumpulan data, penulis mengacu pada sumber studi secara literatur dengan mengutip beberapa referensi pustaka nasional dan internasional dari internet sebagai dasar pembentukan teori untuk mendapatkan sumber-sumber informasi yang jelas dan terukur. Referensi berupa jurnal karya ilmiah yang telah mendapatkan standar lisensi ISSN ataupun jurnal akreditasi terkait penelitian yang diangkat untuk dapat membandingkan sistem-sistem sebelumnya dengan sistem yang akan dirancang oleh penulis pada penelitian Tugas Akhir ini.

\subsection{Metode Pengembangan Sistem (Waterfall)}

Dalam melakukan pengembangan sistem, penulis menggunakan waterfall pada tahap awal membangun sistem. Tahap meliputi tahapan analisis, desain, kode program dan pengujian. Metode ini cukup tua dan sangat matang dalam melakukan tahapan membangun rancangan sistem dan sangat umum digunakan pada peneliti-peneliti sebelumnya yang telah banyak di modifikasi. Metode ini cukup menjadi pilihan bagi para pengembang sistem open source dikarenakan metode ini memiliki konsep secara berurutan, detail dan terstruktur [9].

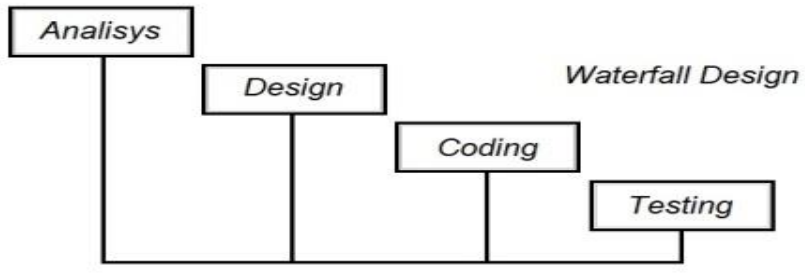

Gambar 1. Metode Waterfall

a. Tahap Analisis Sistem

Analisis sistem digunakan untuk tahapan terjadinya masukan, proses dan keluaran. Menjelaskan spsesifikasi yang dibutuhkan untuk identifikasi pengenalan wajah pada sistem [10]. Tahapan penelitian akan menjelaskan mengenai:

1. Penentuan input-input yang terdapat pada sistem keamanan brangkas menggunakan pengenalan wajah.

2. Penentuan setiap kegiatan proses yang terlibat dalam pengoperasian sistem keamanan menggunakan teknik pendeteksi dan melakukan pencocokan wajah user.

3. Hasil keluaran yang akan ditampilkan pada saat melakukan proses masukan pada sistem ini.

b. Tahap Desain Sistem

Untuk tahap ini digambarkan sebuah perancangan terhadap sistem terkait dengan menggambarkan alur proses kerja sistem berupa diagram alir proses (flowchart) bagaimana terjadinya proses input dan output sistem:

c. Tahap Kode Program

Pada tahap ini adalah tahap dimana proses perancangan telah dibuat sebelumnya. Tahap kode program adalah membuat listing program pada software arduino IDE dengan menggunakan bahasa program Java yang nantinya akan di compile ke dalam chip mikrokontroller arduino agar sistem dapat menjalankan instruksi.

d.Tahap Pengujian Sistem

Tahap ini adalah tahap terakhir pada proses perancangan sistem setelah melewati fase analisa, desain rancangan sistem dan listing program yang telah dibuat. Sistem dilakukan uji coba untuk melihat keberhasilan pada sistem, tahapan pengujian dilakukan untuk:

1. Sistem mampu membuka pintu brangkas secara otomatis dengan scanning wajah dari pengguna.

2. Sistem dapat membaca wajah secara real time, real time disini adalah ketika user menghadap kamera, kunci brangkas akan otomatis langsung merespon terbuka jika tidak terjadi kesalahan pada saat deteksi wajah

\section{HASIL DAN PEMBAHASAN}

Pada penelitian ini, penulis menggunakan algoritma Eigenfaces dalam tahap awal mendeteksi vector citra wajah yang akan digunakan pada proses scanning wajah. Local Binary Pattern ialah teknik untuk mengklasifikasikan 
JURNAL MEDIA INFORMATIKA BUDIDARMA

Volume 4, Nomor 3, Juli 2020, Page 635-641

ISSN 2614-5278 (media cetak), ISSN 2548-8368 (media online)

Available Online at https://ejurnal.stmik-budidarma.ac.id/index.php/mib

DOI 10.30865/mib.v4i3.2149

fitur sebuah wajah manusia serta dikombinasikan dengan fitur histogram dan merupakan teknik baru dari pengembangan metode $L B P$ untuk meningkatkan performa pengenalan wajah. $L P B$ umumnya didesain untuk pengenalan tekstur [11]. $L P B H$ adalah metode yang sangat direkomendasikan untuk melakukan pengenalan citra wajah untuk diimplementasikan pada sistem operasi android karena menggunakan perhitungan yang sederhana. Di satu sisi, karena kapasitas penyimpanan android yang terbatas dan LPBH pun memiliki tingkat akurasi yang cukup besar dari metode-metode pengenalan wajah yang lain [4][12].

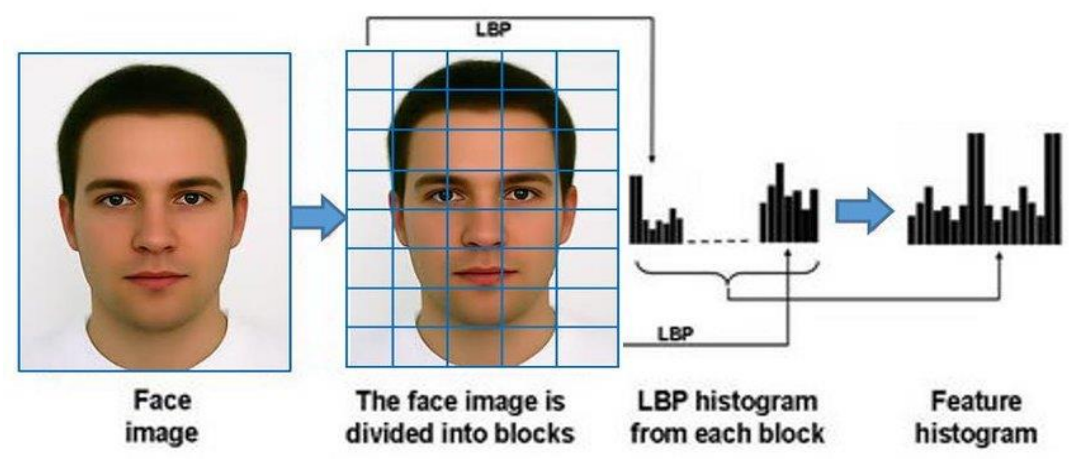

Gambar 2. Local Binary Pattern Histogram

Berikut merupakan algoritma dari sistem yang dirancang.

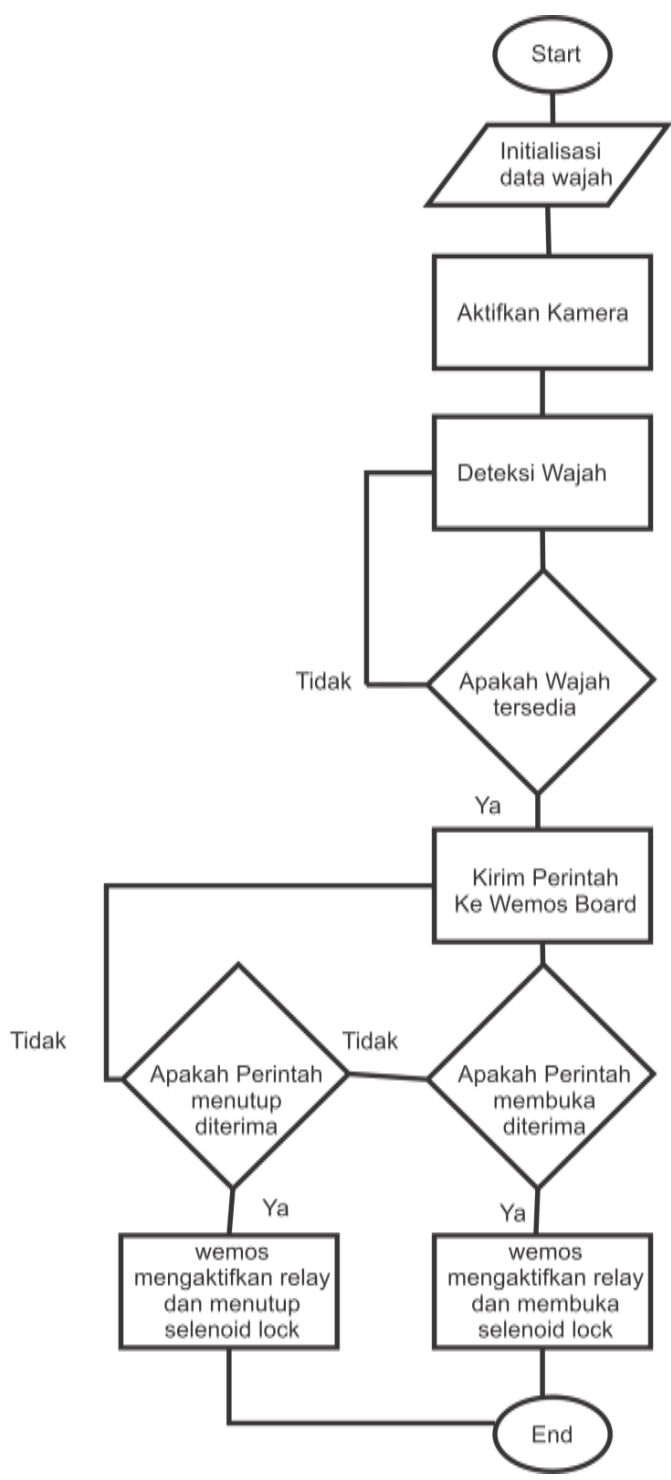

Gambar 3. Flowchart Sistem 
JURNAL MEDIA INFORMATIKA BUDIDARMA

Volume 4, Nomor 3, Juli 2020, Page 635-641

ISSN 2614-5278 (media cetak), ISSN 2548-8368 (media online)

Available Online at https://ejurnal.stmik-budidarma.ac.id/index.php/mib DOI 10.30865/mib.v4i3.2149

\subsection{Pengujian Hardware}

Beberapa Tampilan Saat Sistem Pengenalan Wajah Saat Bekerja :

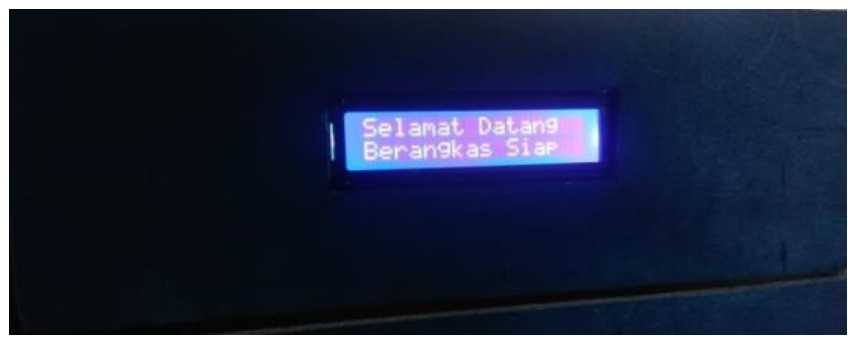

Gambar 4. Tampilan Sambutan

Pada gambar 4 adalah hasil tampilan utama sistem keamanan brangkas menggunakan metode pengenalan wajah dimana setiap pengguna yang akan membuka brangkas akan disambut dengan tampilan berupa tulisan "Selamat Datang, Berangkas Siap" dengan seperti itu pengguna akan tau sistem sudah siap untuk melakukan tugasnya.

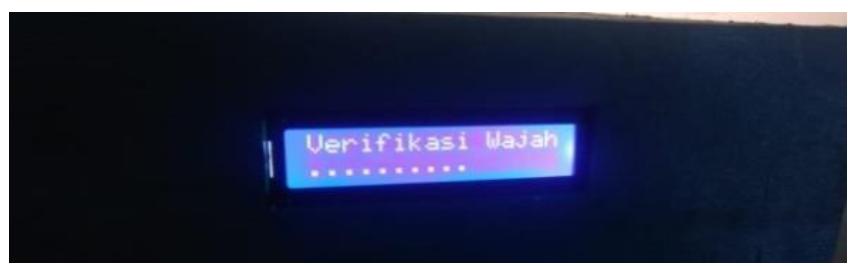

Gambar 5. Tampilan Verifikasi Wajah

Pada gambar 5 adalah hasil tampilan sistem sedang melakukan verifikasi wajah pengguna untuk selanjutnya dimasukan kedalam database dan disimpan jadi ketika pengguna ingin membuka brangkas tidak perlu lagi untuk melakukan verifikasi wajah karena sistem sudah menyimpan wajah pengguna.

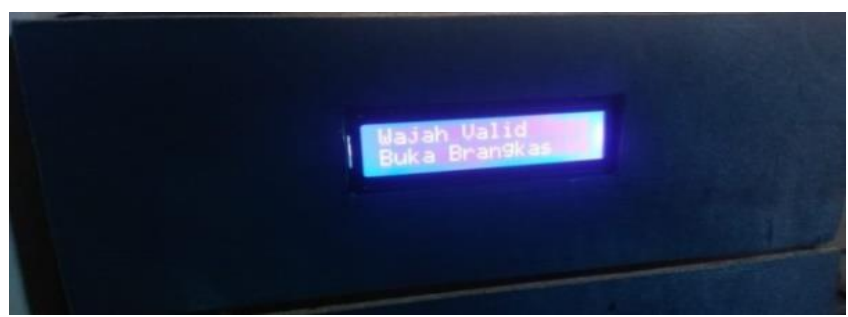

Gambar 6. Tampilan Wajah Valid dan Brangkas Terbuka

Pada gambar 6 adalah hasil tampilan sistem berhasil membaca wajah pengguna sehingga brangkas dapat terbuka dengan baik.

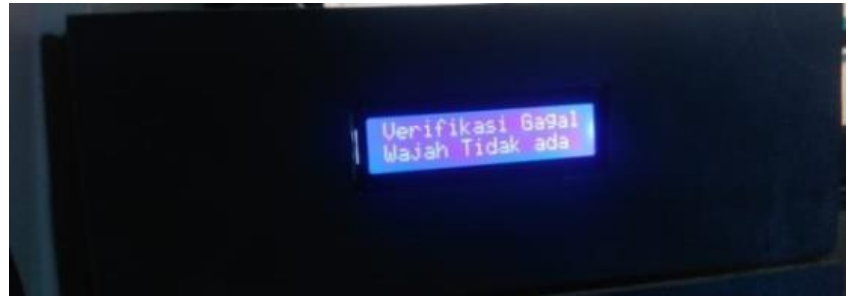

Gambar 7. Tampilan Verifikasi Gagal Sehingga Wajah Pengguna Tidak Terbaca

Pada gambar 7 adalah hasil tampilan sistem tidak dapat membaca wajah pengguna sehingga wajah tidak dapat disimpan pada database dan sistem tidak akan bisa membuka brangkas ketika gagal melakukan verifikasi wajah.

\subsection{Beberapa Hasil Wajah Yang Berhasil Terdaftar:}

Pada gambar dibawah ini terdapat contoh (sample) hasil dari pengujian sistem keamanan brangkas menggunakan face recognition berbasis Android, di lampirkan 4 sample wajah manusia. 
ISSN 2614-5278 (media cetak), ISSN 2548-8368 (media online)

Available Online at https://ejurnal.stmik-budidarma.ac.id/index.php/mib

DOI 10.30865/mib.v4i3.2149
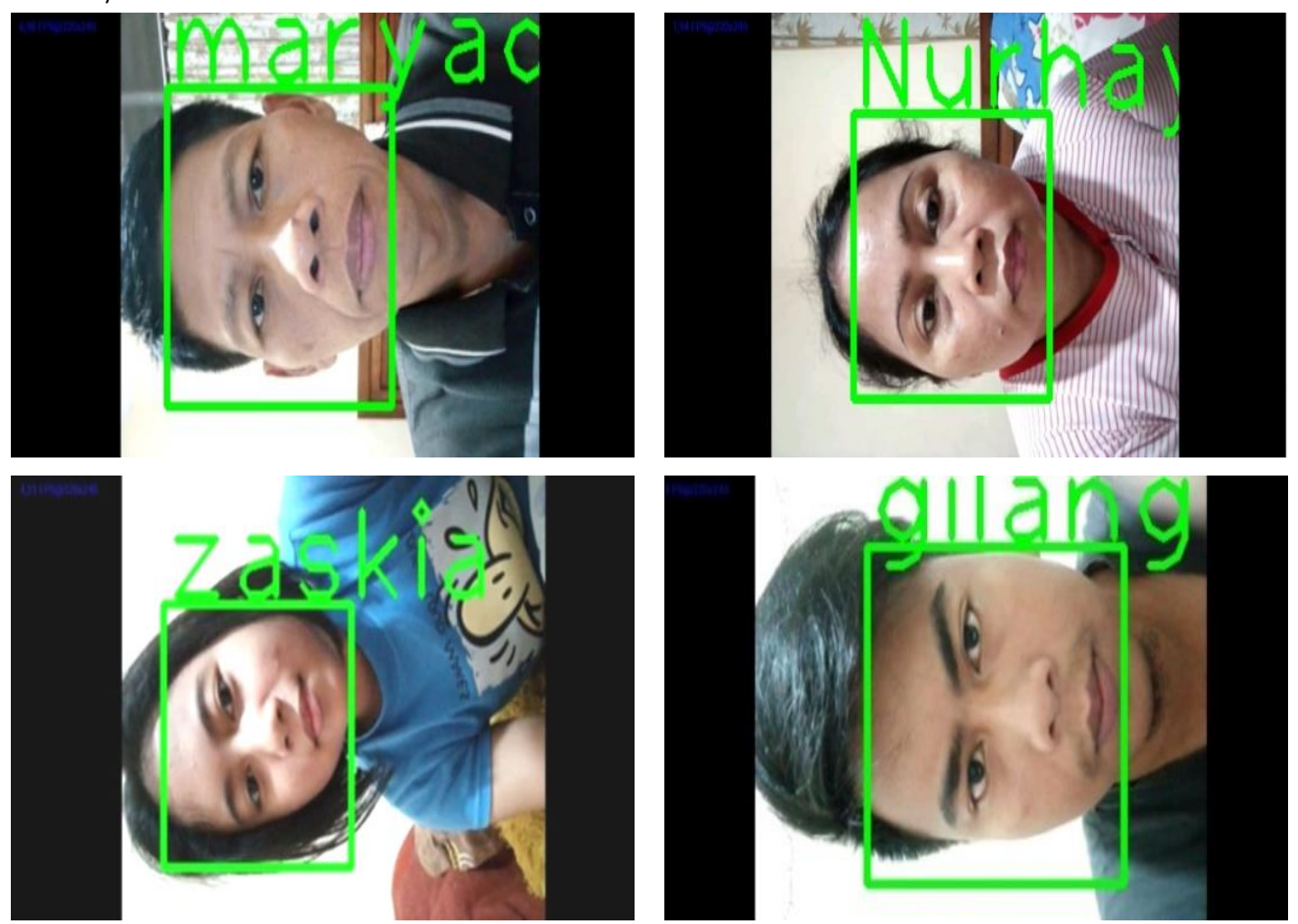

Gambar 8. Wajah User Yang Berhasil Terdaftar

Beberapa Hasil Pengujian Sistem :

a. Hasil Pengujian Grid X dan Grid Y

Tabel 1. Hasil Grid X dan Grid Y

\begin{tabular}{ccc}
\hline Ukuran Grid X dan Grid Y & Akurasi (\%) & Waktu Komputasi (detik) \\
\hline 2 × 2 & 64.44 & 1.45 \\
4 × 4 & 71.11 & 1.53 \\
8 × 8 & 95.56 & 2.35 \\
\hline
\end{tabular}

Keterangan: Dalam pengujian terhadap Grid X dan Grid Y, Grid X sebagai nilai jumlah sel dalam arah horizontal. Semaki banyak sel, semakin halus grid, semakin tinggi dimensi dari vektor fitur yang dihasilkan dan default valu biasanya diatur ke 8 .

b. Pengaruh Radius Terhadap Akurasi

Tabel 2. Hasil Radius Terhadap Akurasi

\begin{tabular}{ccc}
\hline Radius & Akurasi (\%) & Waktu Komputasi (detik) \\
\hline 1 & 95.56 & 2.35 \\
2 & 72.22 & 3.48 \\
3 & 57.78 & 4.51 \\
\hline
\end{tabular}

Keterangan: Berdasarkan hasil pengujian yang ditunjukkan pada Tabel 2 menunjukan bahwa pengaruh radius pad angka 1 memiliki nilai akurasi yang paling tinggi adalah 95,56\%. Semakin kecil ukuran window maka pengaru median filter untuk mengurangi noise semakin sedikit sehingga hasil citra uji masih memiliki banyak noise Sedangkan jika semakin besar maka pengaruh median filter untuk mengurangi noise semaki banyak sehingga informasi- informasi citra uji dianggap noise.

c. Hasil pengujian Neighbors pada Local Binary Pattern Histogram

Tabel 3. Hasil Pengujian Neighbors

\begin{tabular}{ccc}
\hline \hline Neighbors & Akurasi (\%) & Waktu Komputasi (detik) \\
\hline 1 & 95.56 & 2.35 \\
2 & 72.22 & 3.48 \\
3 & 57.78 & 4.51 \\
\hline
\end{tabular}


Keterangan: Pengujian terhadap Neighbors pada dilakukan untuk mengetahui performansi sistem. Pengujian ini dilakukan dengan cara mengubah nilai parameter $\mathrm{N}$. Dimana nilai $\mathrm{N}$ yang digunakan parameter yaitu 1,3,6. Neighbors adalah Jumlah titik sampel untuk membangun pola biner Lokal yang melingkar. semakin banyak titik sampel yang dimasukkan, semakin lama sistem melakukan komputasi.

\section{Kesimpulan Pengujian:}

Berdasarkan hasil pengujian yang ditunjukkan pada Tabel 3 pengaruh parameter nilai $\mathrm{N}$ yang optimal adalah $\mathrm{N}=1$ dengan nilai akurasi yang paling tinggi adalah $95.56 \%$. Hal ini disebabkan karena cara kerja Neighbors mengambil keputusan berdasarkan tetangga terdekat. Semakin kecil nilai N, maka jarak tetangga yang diambil semakin dekat antara data yang ada di database dengan data yang diujikan sehingga hasilnya lebih akurat.

\section{d. Hasil Pengujian Terhadap Jarak}

Pengujian terhadap jarak dilakukan untuk mengetahui jarak paling optimal antara kamera dengan objek seberapa jauh menggunakan sebuah penggaris. Jarak yang akan diuji yaitu, $10 \mathrm{~s} . \mathrm{d} 15 \mathrm{~cm}, 15 \mathrm{~s} . \mathrm{d} 20 \mathrm{~cm}, 20 \mathrm{~s} . \mathrm{d} 25 \mathrm{~cm}$.

Tabel 4. Hasil Pengujian Pada Jarak Kamera ke Objek

\begin{tabular}{ccc}
\hline Jarak (cm) & Akurasi (\%) & Waktu Komputasi (detik) \\
\hline 10 s.d 15 & 81.11 & 3.40 \\
15 s.d 20 & 87.78 & 2.84 \\
20 s.d 25 & 95.56 & 2.35 \\
\hline
\end{tabular}

Keterangan: Berdasarkan hasil pengujian yang ditunjukan pada tabel 4, bahwa pengaruh jarak objek yang paling optimal adalah $20 \mathrm{s.d} 25 \mathrm{~cm}$ dengan tingkat akurasi $95.56 \%$ dan waktu komputasi 2.35 detik.

e. Hasil Keseluruhan dari Pengujian

Tabel 5. Hasil Pengujian

\begin{tabular}{ccccc}
\hline Grid X dan Grid Y & Neighbors & Radius & Jarak (cm) & Akurasi (\%) \\
\hline $8 \times 8$ & 8 & 1 & 20 s.d 25 & 95.56 \\
\hline
\end{tabular}

Keterangan: Berdasarkan hasil pengujian sistem keamanan brangkas dengan menggunakan pengenalan wajah yang dilakukan dengan metode $L P B H$ (Local Binary Pattern Histogram) pada parameter Grid X dan Grid Y = $8 \times 8$, Neighbors $=8$, Radius $=1$, Jarak $=20$ s.d $25 \mathrm{~cm}$ mendapatkan Akurasi $95.56 \%$ dan waktu komputasi 2.35 detik.

Dilakukan pengujian secara fungsional terkait sistem, pengujian ini dilakukan hanya pada saat hasil yang terjadi saat user melakukan scanning wajah pada sistem, apakah wajah mampu melakukan pembukaan pintu brangkas [13].

Tabel 6. Uji Fungsional Sistem

\begin{tabular}{|c|c|c|c|c|c|}
\hline $\begin{array}{l}\text { Kebutuhan } \\
\text { Fungsional }\end{array}$ & $\begin{array}{c}\text { User } \\
1\end{array}$ & $\begin{array}{c}\text { User } \\
2\end{array}$ & $\begin{array}{c}\text { User } \\
\mathbf{3}\end{array}$ & $\begin{array}{c}\text { User } \\
4\end{array}$ & $\begin{array}{c}\text { User } \\
5\end{array}$ \\
\hline $\begin{array}{c}\text { Sistem keamanan brangkas } \\
\text { dapat melakukan proses } \\
\text { pembukaan kunci menggunakan } \\
\text { metode pengenalan wajah }\end{array}$ & $\sqrt{ }$ & $\sqrt{ }$ & $\sqrt{ }$ & $\sqrt{ }$ & $\sqrt{ }$ \\
\hline $\begin{array}{c}\text { Sistem keamanan brangkas mampu } \\
\text { melakukan } \\
\text { pendeteksian } \\
\text { posisi wajah }\end{array}$ & $\sqrt{ }$ & $\mathbf{x}$ & $\sqrt{ }$ & $\sqrt{ }$ & $\sqrt{ }$ \\
\hline $\begin{array}{l}\text { Sistem keamanan brangkas } \\
\text { dapat menyimpan data user } \\
\text { kedalam database }\end{array}$ & $\sqrt{ }$ & $\sqrt{ }$ & $\sqrt{ }$ & $\sqrt{ }$ & $\sqrt{ }$ \\
\hline
\end{tabular}

Keterangan: Berdasarkan Pengujian yang telah dilakukan secara fungsional dengan 3 parameter dilakukan 5x pengujian terhadap 5 user yang berbeda dan 1 dinyatakan tidak dapat di diteksi yaitu pada user ke 2 hal ini terjadi karena pencahayaan kurang terang sehingga tidak termasuk dalam kesalahan sistem internal melainkan eksternal yang dimana penyebab kesalahan berada pada faktor diluar sistem.

\section{KESIMPULAN}

Kesimpulan dari penulis yang dapat diambil dari hasil pengujian pada penelitian sistem keamanan brangkas menggunakan metode pengenalan wajah ini adalah: 
1. Sistem keamanan yang telah dibuat dengan metode pengenalan wajah mampu melakukan proses pembukaan pintu brangkas terhadap user yang telah terdaftar.

2. Berdasarkan hasil pengujian sistem keamanan brangkas dengan menggunakan pengenalan wajah yang dilakukan dengan metode $L P B H$ (Local Binary Pattern Histogram) pada parameter Grid X dan Grid $\mathrm{Y}=8 \times 8$, Neighbors $=8$, Radius $=1$, Jarak $=20$ s.d $25 \mathrm{~cm}$ mendapatkan Akurasi 95.56\% dan waktu komputasi 2.35 detik. Jarak pengambilan gambar yang paling optimal yaitu 20 sampai $25 \mathrm{~cm}$. Apabila citra yang diambil semakin dekat maka citra akan blur. Jika pengambilan citra terlalu jauh maka citra yang tidak dapat terdeteksi.

\section{UCAPAN TERIMA KASIH}

Puji dan syukur saya panjatkan kehadirat Allah SWT, Tuhan Yang Maha Esa atas rahmat, berkah dan hidayahNya sehingga bisa menyusun penelitian ini hingga selesai tepat pada waktunya. Pada kesempatan ini, penulis ingin menyampaikan ucapan terima kasih yang sangat mendalam kepada pihak-pihak yang telah membantu dan mendukung penulis sehingga penulis dapat menyelesaikan penelitian ini dengan baik.

1. Kepala Jurusan Teknik Informatika Nurhayati, S.Si. MTI

2. Dr. Fauziah, S.Kom,.M.M.S.I dan Nurhayati, S.Si, M.Kom selaku pembimbing yang telah membantu dengan memberikan saran dan arahan kepada saya selama pengerjaan penelitian sehingga penelitian bisa selesai dengan baik.

Akhir kata penulis mengharapkan semoga penelitian dapat memberikan manfaat bagi para pembaca dalam rangka menambah wawasan dan semoga Allah SWT, Tuhan Yang Maha Esa memberikan lindungan bagi kita semua.

\section{REFERENCES}

[1] E.P. Dian, H. Agus, "Implementasi Pengenalan Wajah Menggunakan PCA (Principal Component Analysis)," IJEIS, ISSN 2088-3714, vol. 3, no. 2, pp. 175-184, 2013.

[2] S. LEFKOVITS and L. LEFKOVITS, "Performance Analysis of Eigenface Recognition Under Varying External Conditions," Sci. Bull. Petru Maior” Univ. Tîrgu Mureş, vol. 11, no. 2, pp. 44-49, 2014.

[3] K. Mujib, A. Hidayatno, and T. Prakoso, "Pengenalan Wajah Menggunakan Local Binary Pattern (Lbp) Dan Support Vector Machine (Svm)," Transient, vol. 7, no. 1, p. 123, 2018.

[4] A. Fauzan, L. Novamizanti, S. Si, and Y. N. Fuadah, "Implementation Identification of Face Recognition Using LBPH ( Local Binary Pattern Histogram ) Method For Attendance Presence Based Android," e-Proceeding Eng., vol. 5, no. 3, pp. 5403-5413, 2018.

[5] H. Rahmad, W. Agus, "Rancang Bangun Sistem Presensi Menggunakan Face Recognition dengan Metode Eigenface," J. Ilm. Setrum, vol. 7, no. 2, pp. 278-287, 2018.

[6] G. M. Zafaruddin and H. S. Fadewar, "Face recognition using eigenfaces," Adv. Intell. Syst. Comput., vol. 810, no. 5, pp. 855-864, 2018.

[7] Indra, "Sistem Pengenalan Wajah Dengan Metode Eigenface Untuk Absensi Pada PT Florindo Lestari," Semin. Nas. Teknol. Inf. Komun. Terap., pp. 138-144, 2012.

[8] M. Binson, E. Suhartono, N. Kumalasari, C. Pratiwi, F. T. Elektro, and U. Telkom, "Deteksi Derajat Kebengkokan Tulang Belakang Berdasarkan Citra Medis Digital Menggunakan Metode Local Binnary Pattern Dan K-Nearest Neighbor Reference of Rear Bone Grip Detection Based on Digital Medical Image Using Local Binnary Pattern and KNearest Neig," vol. 6, no. 2, pp. 3798-3805, 2019.

[9] I. N. Tri Anindia Putra, "Perancangan dan Pengembangan Sistem Absensi Realtime Melalui Metode Pengenalan Wajah,” JST (Jurnal Sains dan Teknol., vol. 3, no. 2, pp. 450-467, 2015.

[10] Y. Arkhiansyah and D. Setiawan, "Realisasi Cetv Cerdas Berbasis Mikrokontroler Dan Real Time 3D Face Recognition,” J. Inform., vol. 15, no. 2, pp. 188-197, 2015.

[11] D. Retnoningrum, A. W. Widodo, and M. A. Rahman, "Ekstraksi Ciri Pada Telapak Tangan Dengan Metode Local Binary Pattern ( LBP )," vol. 3, no. 3, pp. 2611-2618, 2019.

[12] A. Guru Sai Sasidhar and P. Jagadeesh, "Face tracking and recognition using matlab and arduino," Int. J. Eng. Adv. Technol., vol. 8, no. 6 Special issue, pp. 231-234, 2019.

[13] D. Aryani, M. N. Ihsan, and P. Septiyani, "Prototype Sistem Absensi Dengan Metode Face Recognition Berbasis Arduino Pada Smk Negeri 5 Kabupaten Tangerang,” Semnasteknomedia Online, vol. 5, no. 1, pp. 1-3-37, 2017. 